\title{
Note
}

\section{Molecular-based method to distinguish sympatric deep-sea whelks, Buccinum striatissimum and Buccinum tenuissimum in the Sea of Japan} \author{
\& ISAO HAYASHI ${ }^{1}$ \\ ${ }^{1}$ Division of Applied Biosciences, Graduate School of Agriculture, Kyoto University, Kyoto 606-8502, Japan \\ ${ }^{2}$ Field Science Education and Research Center, Kyoto University, Kyoto, 606-8502, Japan \\ ${ }^{3}$ Toyama Prefecture Fisheries Research Institute, Toyama 936-8536, Japan \\ ${ }^{4}$ Japan Sea National Fisheries Research Institute, Niigata 951-8121, Japan
}

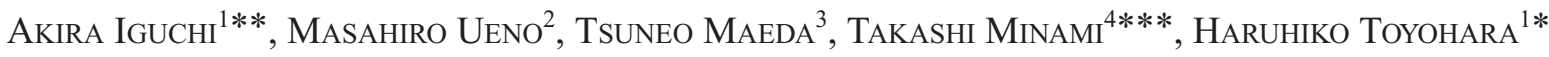

Received 16 November 2007; Accepted 26 March 2008

\begin{abstract}
Buccinum striatissimum and Buccinum tenuissimum are commercially important whelks in the Sea of Japan. B. striatissimum is very similar to B. tenuissimum and their morphological variations make the identification of these species difficult, especially in case that these species are caught together because they are subject to the same environmental factors. In order to develop an easy and objective method to delineate these species, we utilized the difference of mitochondrial 16SrDNA of these two species. As a result, we could easily distinguish these two species by PCR-RFLP method using the difference of this region and AseI restriction endonuclease. In addition, we succeeded in distinguishing sympatric samples of these species, which suggests that these two species are likely to be reproductively isolated although the possibility of hybridization can not be completely ruled out.
\end{abstract}

Key words: Buccinum, sympatry, 16SrDNA, PCR-RFLP, the Sea of Japan

In the Sea of Japan, four Buccinum species (Buccinum bayani Jousseaume, 1883; Buccinum striatissimum Sowerby, 1899; Buccinum tenuissimum Kuroda in Teramachi, 1933; Buccinum tsubai Kuroda in Teramachi, 1933) are commercially important for the deep bottom fisheries (Kato 1979). In particular, B. tenuissimum is the most valuable among them (Kato 1981, Maeda \& Doi 2006). However, the wide range of morphological variations often makes the identification of these species difficult (Amano \& Watanabe 2001, Kato 1979), especially in cases where these species are caught together because they are subject to the same environmental factors. $B$. striatissimum usually inhabits shallower regions (200-590 m) than B. tenuissimum (350-1550 m), and they also show sympatry around 400-500 $\mathrm{m}$ (Iguchi et al. unpublished data, Kato et al. 1979). It is usually easy to distinguish these two species based on shell thickness and depth of suture (Iguchi et al.

\footnotetext{
* Corresponding author: Haruhiko Toyohara; Email: toyohara@kais.kyotou.ac.jp

** Present address: Comparative Genomics Centre, Molecular Science Building, James Cook University, Australia, Townsville, Queensland, 4811, Australia

*** Present address: Laboratory of Fisheries Biology and Ecology, Faculty of Agricultural Science, Tohoku University, 1-1 Tsutsumidori, Amamiyamachi, Aobaku, Sendai, Miyagi 981-8555, Japan
}

2007), but $B$. striatissimum shows very thin shell thickness and is very similar to $B$. tenuissimum in places where they are caught together (Fig. 1). In such a case, it is very difficult to distinguish these species without enough taxonomical experiences. Even if they could be distinguished by morphological differences, it would be unclear whether they are genetically different from each other considering their ambiguous mor-
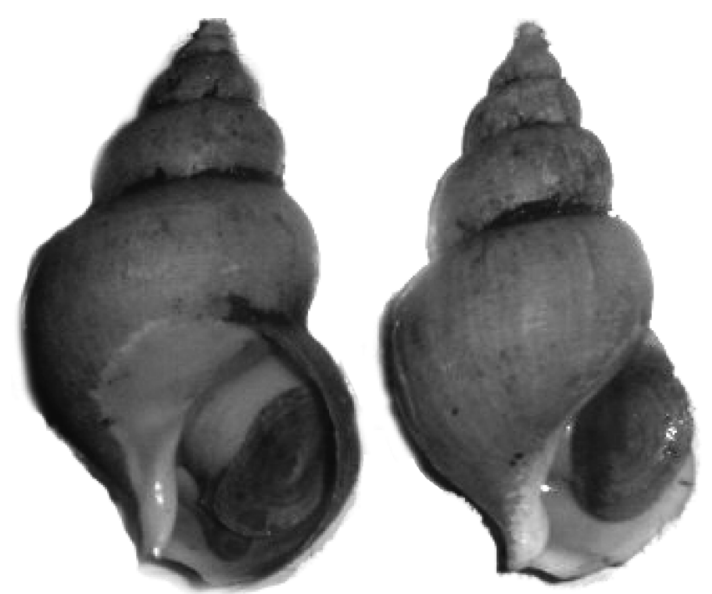

Fig. 1. Shells of sympatric Buccinum tenuissimum (left) and Buccinum striatissimum (right). 


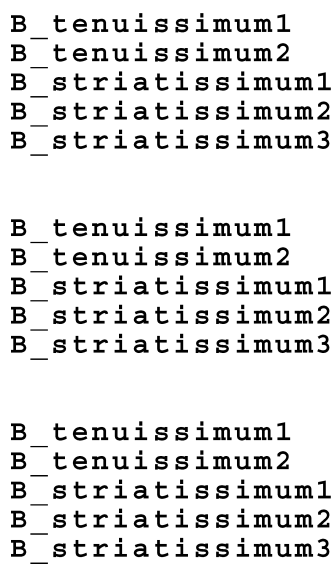

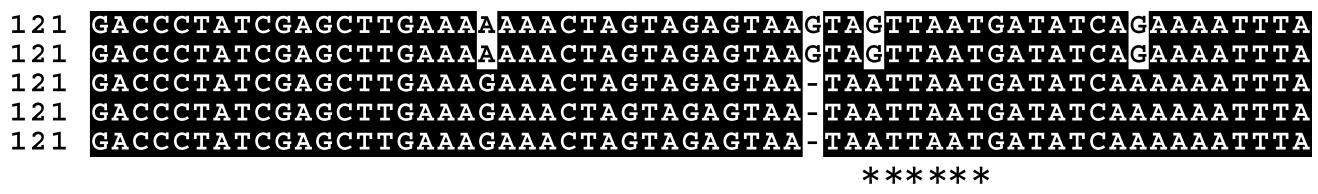

181 CTATTAGAAATTTAGTTGGGCGACTAAGGAACAAAAAAAGCTTCCTTTAAAAATAAA

181 CTATTAGAAATTTAGTTGGGGCGACTAAGGAACAAAAAAAGCTTCCTTTAAGAATTAA

180 CTATTAGAAATTTAGTTGGGGCGACTAAGGAACAAAAAAAGCTTCCTTTAAAATTAAA

180 CTATTAGAAATTTAGTTGGGGCGACTAAGGAACAAAAAAAGCTTCCTTTAAAAACTAAA

180 CTATTAGAAATTTAGTTGGGCGACTAAGGAACAAAAAAAGCTTCCTTAAAAATAAA

Fig. 2. Alignment of 5 sequences of the 16SrDNA region of Buccinum striatissimum and Buccinum tenuissimum. Numbers to the left of each block denote the position in the matrix. Each name corresponds to the sequence of the accession number available from the DNA Data Bank of Japan below; B_tenuissimum1: AB183330; B_tenuissimum2: AB183331; B_striatissimum1-3: AB183334-AB183336. Predicted restriction site of AseI is shown by asterisks.

phological variations. Thus, an easy and objective method to delineate these species should be developed. In a previous study, we found that $B$. striatissimum is clearly different from $B$. tenuissimum in mitochondrial 16SrDNA sequence analysis (Iguchi et al. 2007). By utilizing this difference, we tried to develop a polymerase chain reaction-restriction fragment length polymorphism (PCR-RFLP) method to distinguish sympatric B. stiriatissimum and B. tenuissimum.

In order to search for the sequence to distinguish $B$. striatissimum and $B$. tenuissimum, we aligned five 16SrDNA sequences of these two species reported in our previous study (Iguchi et al. 2007) using the computer software CLUSTAL X (Thompson et al. 1997). The alignment is shown in Fig. 2, which demonstrates that $B$. striatissimum is different from $B$. tenuissimum in the sequence of ATTAAT (Fig. 2). Accordingly, we selected AseI as a candidate restriction endonuclease for our PCR-RFLP analysis. Three individuals of each typical B. striatissimum and B. tenuissimum samples (see Iguchi et al. 2007) were collected from the Sea of Japan (B. striatissimum, $36^{\circ} 30.92^{\prime} \mathrm{N}, 136^{\circ} 01.04^{\prime} \mathrm{E}$, depth $300 \mathrm{~m} ; \quad B$. tenuissimum, Toyama Bay). All specimens were kept in a freezer $\left(-20^{\circ} \mathrm{C}\right)$ prior to analysis. DNA extraction, PCR procedures followed our previous methods (Iguchi et al. 2004). A total of $15 \mu \mathrm{L}$ of each PCR product was digested with 6-bp-recognizing restriction endonuclease, AseI (recognition sequence: AT/TAAT) at $50^{\circ} \mathrm{C}$ over night. Treated PCR products were used for $2 \%$ agarose gel electrophoresis, and visualized with ethidium bromide under ultraviolet light. In addition, we collected sympatric samples of one individual of $B$. striatissimum and three individuals of $B$. tenuissimum from the Sea of Japan $\left(36^{\circ} 17.78^{\prime} \mathrm{N}, 135^{\circ} 30.89^{\prime} \mathrm{E}\right.$, depth $\left.520 \mathrm{~m}\right)$. Species identification was mainly based on the depth of suture (Iguchi et al. 2007). These samples were also treated as described above to perform PCR-RFLP analysis.

As expected from the result of alignment, three individuals of B. striatissimum showed two bands (200-bp, 261-bp) and

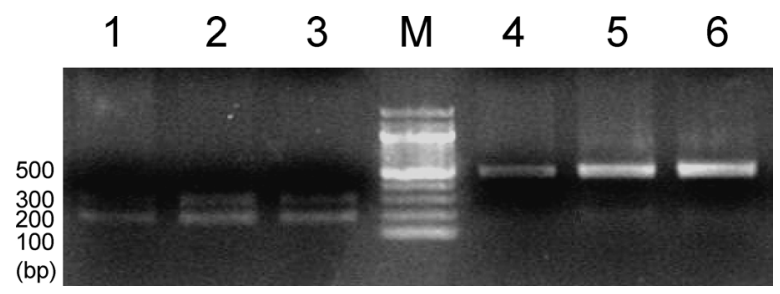

Fig. 3. PCR-RFLP analysis of the 16 SrDNA region of typical Buccinum striatissimum and Buccinum tenuissimum. Lane designations are as follows: M, 100-bp DNA ladder (BioLabs); 1-3, B. striatissimum; 4-6, B. tenuissimum.

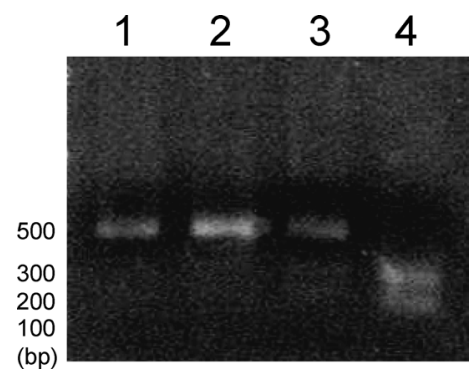

Fig. 4. PCR-RFLP analysis of the 16SrDNA region of sympatric Buccinum striatissimum and Buccinum tenuissimum. Lane designations are as follows: 1-3, B. tenuissimum; 4, B. striatissimum.

three ones of B. tenuissimum a single band (462-bp, Fig. 3). Thus, we can distinguish these two species by this PCR-RFLP method using mitochondrial 16SrDNA region and AseI restriction endonuclease. In addition to these six samples, six individuals of $B$. striatissimum and 11 ones of B. tenuissimum collected from the Sea of Japan had the same types of sequences characterized by "ATTAAT" in B. striatussimum and "GTTAAT" in B. tenuissimum (Iguchi et al. 2007, unpublished data). Thus, this PCR-RFLP method is reliable approach to 
distinguish these two species. The result of PCR-RFLP analysis of sympatric samples of $B$. striatissimum and B. tenuissimum is shown in Fig. 4. In the lane of B. tenuissimum, single band was detected, and in the lane of B. striatissimum, two bands were found. The result strongly supports that $B$. striatissimum and $B$. tenuissimum clearly show sympatry, which suggests that these two species are likely to be reproductively isolated. However, considering the low number of specimens used in this study, more samples should be analyzed by using the method developed here and direct-sequencing because introgressive hybridization might be occurring between these two species in sympatric area. PCR-RFLP method is rapid and cost-effective method (Borgo et al. 1996, Hosoi et al. 2004). The method developed here would enable us not only to distinguish these commercially important deep-sea whelks, but also to examine the large number of samples for analysis of genetic structure of Buccinum species easily.

\section{Acknowledgment}

We thank Captain K. Niu and the officers and crew of the TanshuMaru (Kasumi high school), and T. Hirose (Japan Sea National Fisheries Research Institute) for their help in sampling.

\section{References}

Amano K, Watanabe M (2001) Taxonomy and distribution of Plio-Pleistocene Buccinum (Gastropoda: Buccinidae) in northeast Japan. Paleontol Res 5: 215-226.

Borgo R, Souty-Grosset C, Bouchon D, Gomot L (1996) PCR-RFLP analysis of mitochondrial DNA for identification of snail meat species. J Food Sci 61: 1-4.

Hosoi M, Hosoi-Tanabe S, Sawada H, Ueno M, Toyohara H, Hayashi I (2004) Sequence and polymerase chain reaction-restriction fragment length polymorphism analysis of the large subunit rRNA gene of bivalve: Simple and widely applicable technique for multiple species identification of bivalve larva. Fish Sci 70: 629-637.

Iguchi A, Ueno M, Maeda T, Minami T, Hayashi I (2004) Genetic population structure of the deep-sea whelk Buccinum tsubai in the Japan Sea. Fish Sci 70: 569-572.

Iguchi A, Ito H, Ueno M, Maeda T, Minami T, Hayashi I (2007) Molecular phylogeny of deep-sea Buccinum species (Gastropoda: Buccinidae) around Japan. Mol Phyl Evol 44: 1342-1345.

Kato F (1979) Studies on the distribution of four species of edible deep sea whelk (Mollusca, Buccinidae) in the Japan Sea. Bull Jap Sea Reg Fish Res Lab 30: 15-27.

Kato F (1981) 3-2. Fishing grounds in the Sea of Japan. In: Fisheries Science Series 36: Pot Fishery (ed Japanese Society of Fisheries Science). Koseisha-Koseikaku, Tokyo, pp. 80-97.

Maeda T, Doi S (2006) Size at sexual maturity of a deep-sea whelk, Buccinum tenuissimum, in the Sea of Japan. Bull Toyama Prefectural Fish Res Institute 17: 1-9.

Thompson JD, Gibson TJ, Plewniak F, Jeanmougin F, Higgins DG (1997) The ClustalX windows interface: flexible strategies for multiple sequence alignment aided by quality analysis tools. Nucleic Acids Res 24: 4876-4882. 